\title{
Resenhas
}





\section{Do poder ao governo e do saber à veridição}

Monica Loyola Stival | Universidade Federal de São Carlos

Michel Foucault, Du gouvernement des vivants, cours au Collège de France, 1979-1980, Édition établie sous la direction de François Ewald et Alessandro Fontana, par Michel Senellart, Paris: EHESS/Gallimard/ Seuil, 2012, 385p.

Um lugar-comum na periodização dos trabalhos de Michel Foucault tende a distinguir três momentos, um arqueológico (década de 1960), outro genealógico (anos 1970) e um último momento, dedicado às técnicas de si (anos 1980). Esse tipo de divisão costuma colocar dificuldades aos comentadores, já que é preciso compreender o sentido das transições ou "deslocamentos", como se gosta de dizer, no interior do desenvolvimento geral de pesquisa. Por isso, diversos trabalhos recentes sobre a obra de Foucault têm colocado essa divisão em questão. Com efeito, para refinar a compreensão da natureza e sentido das inflexões no fluxo das pesquisas de Foucault, creio que é preciso considerar atentamente o livro Du gouvernement des vivants, publicado em novembro de 2012.

Trata-se do curso ministrado por Foucault em 1979-1980 no Collège de France. A recente publicação é organizada por Michel Senellart, e faz parte do projeto geral de editar todos os cursos proferidos por Foucault naquela instituição. Senellart ficou responsável por escrever uma pequena apresentação do curso, a Situation du cours, que consta ao final do volume. Nessa apresentação encontramos uma retomada esclarecedora da estrutura geral do curso e de seus principais conceitos. Senellart resume essa estrutura, composta de duas partes, uma dedicada à análise do Édipo Rei e outra, maior, centrada na análise do cristianismo 
(Foucault, 2012, p. 324). Tais análises têm como problema teórico o "governo dos homens pela verdade" (Ibid., p. 12).

Segundo Senellart, a formulação deste tema é signo de uma mudança em relação aos trabalhos anteriores, particularmente visível na diferença entre a formulação "governo dos homens pela verdade" e aquela que, apresentada na primavera de 1979, dá titulo ao curso, "governo dos vivos". Essa leitura reforça a sensação, bastante difundida, de que Foucault passa, juntamente com a mudança de década, a outro tema, a outro conjunto de questões. Se, aparentemente, considerando-se o título "Du gouvernement des vivants", o curso dá continuidade às análises feitas em Sécurité, Territoire, Population (1977-1978) e Naissance de la Biopolitique (1978-1979), Senellart entende que "é de outra coisa, enfim, que se trata no curso pronunciado em 1980" (Ibid., p. 324). Entretanto, embora a perspectiva da verdade enfatize o sujeito e não tanto o "corpo-espécie", nada mais natural à démarche dos trabalhos de Foucault do que a consideração das manifestações de verdade. Afinal, assim como nos dois anos precedentes, é do sentido do governo que se trata, como atesta a formulação do próprio Foucault em seu Résumé du cours, onde esclarece que "o curso deste ano apoiou-se nas análises realizadas nos anos precedentes, a propósito da noção de 'governo': esta noção é entendida no sentido amplo de técnicas e procedimentos destinados a dirigir a conduta dos homens" (Ibid., p. 317).

Nada menos abrupto, portanto, que a passagem do curso Naissance de la biopolitique ao curso Du gouvernement des vivants, ao contrário do que faria esperar a vulgata das rupturas e dos deslocamentos substantivos. Se a questão central, em 1980, é a manifestação da verdade, é porque este é o correlato do exercício do poder. Correlação que está presente no objeto de 1979, o liberalismo, já que asserções sobre o "corpo-espécie" (população) não significam a neutralidade, para essas asserções, do sujeito. Afinal, desde 1978 Foucault procura investigar a "constituição típica do sujeito ocidental moderno” (Foucault, 2004b, p. 188). A questão, para Foucault, é que a todo regime político corresponde uma 
epistemologia do sujeito. Assim, o estudo do exercício do poder, da chamada "governamentalidade" liberal, realizado particularmente em 1979, mostra que o "homo oeconomicus é justamente aquilo que é manejável, como aquilo que responde, de forma sistemática, a modificações introduzidas artificialmente em seu meio" (Id., 2004a, p. 274) . É um processo de subjetivação que está em jogo, e é esse mesmo processo que continua em jogo em 1980. Foucault mostra que o liberalismo norte-americano, em especial o dos economistas da Escola de Chicago, como Friedmann, Becker e Lucas, muito além de um programa econômico ou político, é "toda uma maneira de ser e de pensar" (Ibid., p. 224). Talvez a crença em uma ruptura nesse momento dos trabalhos de Foucault deva-se a uma leitura ingênua do curso de 1979, acreditando que a análise do liberalismo significa apenas a compreensão de certo exercício de poder, ignorando o sentido dessa "maneira de ser e de pensar", desse êthos liberal.

Para Foucault, em 1979, no curso Naissance de la biopoliti$q u e$, importa mais o sujeito do liberalismo do que o liberalismo como regime político. Ou, melhor dizendo, importa esse regime na medida em que ele envolve certa epistemologia do sujeito, na qual a ambiguidade entre ser sujeito e ser objeto é análoga à ambiguidade da população como sujeito e como objeto. O tipo de constrangimento e de obrigações que um regime político veicula (sujeição) tem como correlato certo regime de verdade (subjetivação). Nas palavras de Foucault, "o regime de saber é o ponto no qual se articulam um regime político de obrigações e de constrangimentos e esse regime de obrigações e de constrangimentos particular que é o regime de verdade" (Id., 2012, p. 99).

1 Governamentalidade é um neologismo criado por Foucault e significa "o conjunto constituído pelas instituições, os procedimentos, análises e reflexões, os cálculos e as táticas que permitem exercer essa forma bem específica, embora muito complexa, de poder que tem por alvo principal a população, por principal forma de saber a economia política e por instrumento técnico essencial os dispositivos de segurança" (Foucault, 2004b, p. 111). 
Se vemos assim que, em 1979, o conceito de poder dá lugar à noção mais sofisticada de governo, é preciso, por outro lado, aprofundar o conceito de saber em direção à manifestação da verdade. (Do poder ao governo e do saber à veridição. Paris: Vrin, 2015)2. Esse passo não significa, portanto, qualquer inflexão maior no trabalho de Foucault, mas apenas o complemento de uma investigação já em curso, uma vez que se trata da "manifestação da verdade correlata ao exercício de poder” (Ibid., p. 8). Ou, para usar os termos específicos de Foucault em 1980, trata-se da "aleturgia correlata à hegemonia"3. O objeto é a correlação, a articulação, e não há, então, substituição de um tema por outro. O cristianismo, assim como o liberalismo, é um exemplo da ideia geral de que "é verossímil que não haja nenhuma hegemonia que possa se exercer sem alguma coisa como uma aleturgia” (Ibid., p. 14). Para colocar o problema da correlação entre exercício de governo e manifestação da verdade é preciso evitar a redução do problema à análise exclusiva de um desses elementos.

Foucault nota que há um excedente no nível epistemológico em relação ao regime político. Para isso, ele se coloca em um plano anterior àquele de Maquiavel, já que "esse verdadeiro, cuja manifestação acompanha o exercício do poder, ultrapassa amplamente os conhecimentos que são úteis para o governo" (Ibid., p. 6). Desde Maquiavel, parece predominar na filosofia política a dimensão do exercício do poder, a hegemonia, perdendo-se de vista a correlação. Daí a necessidade, para Foucault, de forjar o termo "aleturgia" para referir-se ao correlato daquele exercício. "Aleturgia" e não "resistência", pois não se trata apenas da oposi-

2 O termo veridição é usado por Foucault para designar a manifestação ou produção da verdade, a constituição do discurso verdadeiro.

3 Segundo a explicação que Foucault fornece para esse neologismo, forjando "a palavra fictícia alêthourgia, a aleturgia, poderíamos chamar 'aleturgia' o conjunto dos procedimentos possíveis, verbais ou não, pelos quais trazemos à luz o que é posto como verdadeiro por oposição ao falso, ao escondido, ao indizível, ao imprevisível, ao esquecido" (Foucault, 2012, p. 8). 
ção complementar de forças, mas de verdade, de subjetivação em diferentes regimes. Por isso há aquele excedente, e "do político ao epistemológico, a relação a estabelecer não deve ser estabelecida em termos de ideologia, não deve ser estabelecida tampouco em termos de utilidade" (Ibid., p. 99).

Segundo Foucault, não se trata da "concentração dos conhecimentos úteis para governar eficazmente", pois há algo como "um suplemento em relação a essa economia da utilidade" (Ibid., p. 23). Esse suplemento, esse excedente "não econômico" (Ibid., p. 7), é o que exige certa sofisticação da noção de saber na economia da obra foucaultiana. Em 1980, Foucault dá continuidade à operação que iniciara em meados dos anos 1970, na tentativa de aprofundar a noção geral de saber-poder em direção às noções de governo e de veridição (ou governo pela verdade). Se a obra de Foucault pretende realizar um deslocamento em relação ao modelo da "ideologia dominante", um segundo deslocamento - este interno à obra - já está em operação há pelo menos dois anos. "Dois deslocamentos sucessivos, se quiserem: um, passando da noção de ideologia dominante àquela de saber-poder, e depois, agora, segundo deslocamento, da noção de saber-poder à noção de governo pela verdade" (Ibid., p. 12). É um momento importante deste segundo movimento o que o leitor encontra em Du gouvernement des vivants, aprofundando a noção de "governo" "que me parece ser muito mais operatória que a noção de poder”, diz Foucault) (Ibid., p. 13).

A passagem do poder ao governo é acompanhada por uma passagem do saber à veridição, dado que a correlação entre esses níveis é imediata. Foucault quer mostrar, afinal, de que modo "não se pode dirigir os homens sem fazer operações na ordem do verdadeiro, operações sempre excedentes (excédentaires) em relação ao que é útil e necessário para governar de uma maneira eficaz" (Ibid., p. 18). Como mostra o curso de 1979, especialmente a explicitação do êthos liberal norte-americano, o próprio neoliberalismo evoca esse excedente em relação a certa racionalidade instrumental, entendendo que não se pode reduzir a política a um 
resultado mais ou menos contingente da escolha racional. Embora o cálculo seja essencial à arte de governar moderna, o êxito que fornece a medida de seu sucesso depende não apenas de conhecimentos que favoreçam a utilidade. Nesse sentido, Foucault mostra em 1979 como a perspectiva de Hayek evidencia o fato de que “o liberalismo também necessita de utopia” (Id., 2004a, p. 225). O curso de 1980 traz ao primeiro plano esse excedente. Afinal, para Foucault, "é sempre além da finalidade do governo e dos meios eficazes para alcançá-los que a manifestação de verdade é requerida para, ou é implicada pela, ou é ligada à atividade de governar e de exercer o poder" (Id., 2012, p. 18). Lição que Foucault permite deixar para as análises políticas: é preciso ir além da reflexão sobre meios e fins de governo. É preciso complementar a reflexão sobre a hegemonia com uma análise da aleturgia que a acompanha.

O curso de 1980 não trata, propriamente, da aleturgia moderna, mas da constituição de uma forma de aleturgia que define traços essenciais desta última. Trata-se da "autoaleturgia" (Ibid., p. 52), isto é, da manifestação da verdade que tem como principal característica a introdução do "eu" (je). Por isso o curso inicia-se com uma discussão sobre o Édipo Rei. Momento da primeira formulação desse modo de manifestação da verdade, o Édipo Rei serve como exemplo para Foucault chegar ao caso específico de relação entre hegemonia e aleturgia que o ocupa nesse curso, o caso do cristianismo. Isso porque a posição do "eu" no centro da manifestação de verdade inaugura a ambiguidade da condução, do governo (conduzir e conduzir-se). Portanto, a pergunta que atravessa o curso - e cuja resposta envolve, genealogicamente, o Édipo Rei e, sobretudo, o cristianismo - é

por que e como o exercício do poder em nossa sociedade, o exercício do poder como governo dos homens, requer não apenas atos de obediência e submissão, mas atos de verdade nos quais os indivíduos, que são súditos nas relações de poder, são tanto súditos como atores, espectadores testemunhas ou objetos no procedimento de manifestação de verdade? (Ibid., pp. 8o-88). 
A reflexividade em questão, nos "atos de verdade", permite que se compreenda de que modo a obediência pode ter valor positivo (Ibid., p. 319), o que não é nada irrelevante para situar a constituição histórica da dimensão em que se define o que é ou não aceitável, em que se define a legitimidade do poder. No nível da veridição, Foucault reforça a tese geral de diversos trabalhos, segundo a qual "não há legitimidade intrínseca ao poder" (Ibid., p. 76). Do ponto de vista metodológico, trata-se, em 1980, mais uma vez, de não partir dos universais ou, o que é o mesmo, de “colocar o não-poder, ou a não-aceitabilidade do poder, não ao termo da empreitada, mas no início do trabalho, sob a forma de uma colocação em questão de todos os modos segundo os quais efetivamente aceita-se o poder" (Ibid., p. 77).

Du gouvernement des vivants é assim um curso crucial para esclarecer o nível em que Foucault pretende situar suas análises do poder, do saber, do sujeito: na articulação que constitui a forma concreta de cada uma dessas noções, aquém do problema imediato (mas não sem importância) de valorar um regime político. O perigo talvez esteja, é verdade, em não passar de um nível a outro, zerando a dinâmica da disputa ao fazê-la objeto. Entretanto, Foucault quer mostrar que não se pode também resignar-se à análise do exercício de poder, recusando a relevância da manifestação de verdade que o acompanha e que, no limite, define a legitimidade que aquele requer.

Referências bibliográficas

FOUCAULT, M. Du gouvernement des vivants: Cours au Collège de France, 1979-1980. Paris: EHESS/Gallimard/Seuil, 2012. - Naissance de la biopolitique: Cours au Collège de France, 1978-1979, Paris: Hautes Études/Gallimard/Seuil, $2004 a$.

Sécurité, Territoire, Population: Cours au Collège de France, 1977-1978. Paris: Hautes Études/Gallimard/Seuil, $2004 \mathrm{~b}$. 
